\title{
11. Zeolites and MOFs as Catalysts in Fine Chemical Reactions
}

\author{
Francisco G. Cirujano ${ }^{1}$ and Anna Nowacka ${ }^{2}$ \\ ${ }^{1}$ Centre for Surface Chemistry and Catalysis, KU Leuven. \\ ${ }^{2}$ Instituto de Tecnología Química, Universitat Politècnica de \\ València-Consejo Superior de Investigaciones Científicas.
}

Keywords: Turnover frequency (TOF), stereoselectivity, isomerization, selective oxidation, reduction

\section{Introduction}

During the last centuries, many people did not survive diseases that can be easily treated today by the use of pharmaceuticals such as antibiotics. On the contrary, this century developed countries face an aging revolution, suffering from neurodegenerative diseases and a higher proliferation of different types of cancers. The industrial synthesis of fine chemicals such as pharmaceuticals, perfumes, cosmetics and flavourings is a trillion dollar market with the aim of finding solution to such health problems. Although every year new drugs appear in order to better treat this problems, the high complexity of the pharmacologically active compounds requires expensive and hazarous chemical processes to produce them, which has a negative environmental impact. Due to the large volume of production and, more importantly, the high cost of the processes, it is necessary to develop more efficient catalysts able to increase the yield of the desired product. In relation to the low efficiency of the synthesis of pharmaceuticals, it is estimated that the kilograms of residue generated per kilogram of pharmaceutical component is between 20 and 100 (see E factor later on this chapter). Obviously it is contradictory that in order to solve health problems, we are affecting our health by the way we are doing those chemical processes.

If we observe nature, we find that bioactive compounds are naturally produced by plants, using just water and minerals from the soil and $\mathrm{CO}_{2}$ from the air. Their chemical synthesis under the most efficient and clean imaginable ways is possible by microscopic machines present in all cells 


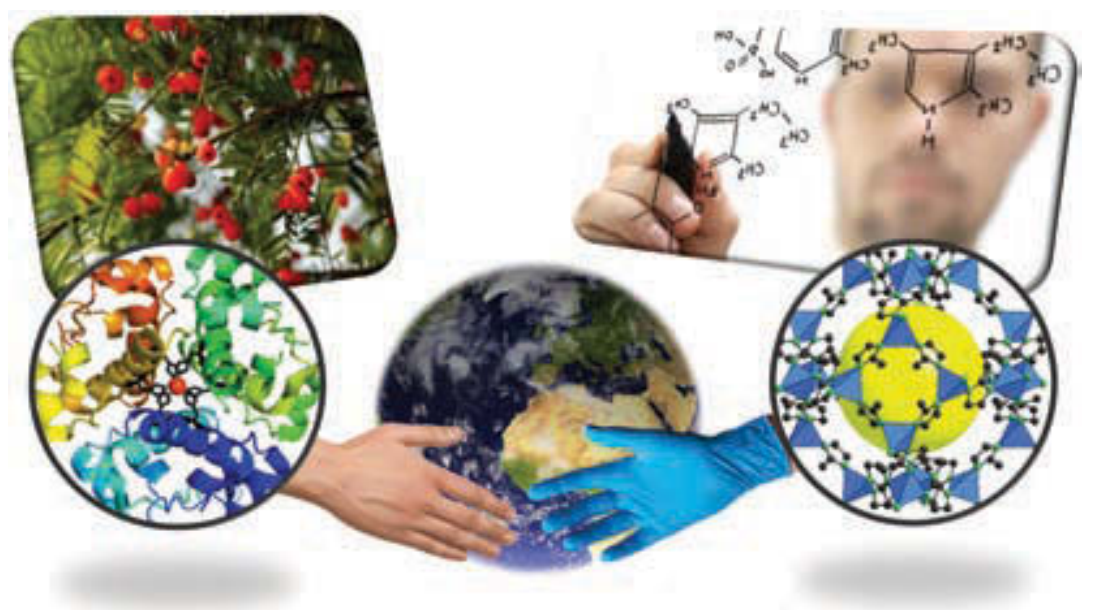

Figure 1. Sustainable synthesis of pharmaceuticals and fine chemicals through the use of porous materials designed and synthesized with structures and functionalities similar to those found in natural enzymes. Adapted with permission from Acc. Chem. Res., 2010, 43, 58. Copyright 2010 American Chemical Society.

of living creatures. These naturally evolved materials, known as enzymes, are able to perform the synthesis of complex molecules that find application as pharmaceuticals. By bonding together different building blocks in a porous solid, we use them as catalysts to promote the synthesis of pharmaceutically active compounds by clean chemical reactions under mild conditions. The materials have a sponge like porous structure that absorb and concentrate the pharmaceutical precursors. This favours the synthetic chemical reactions inside the material pores, which act as microscopic cages with dimensions similar to that of the desired pharmaceutical molecule. The final goal is to be as efficient as natural enzymes using more robust materials that withstand a broader range of reaction conditions, minimizing the environmental impact of the chemical transformations employed to produce affordable pharmaceutical treatments for future generations (Figure 1).

Therefore, selective catalysts are used to minimize the amount of by-products, behaving in a similar way to natural enzymes. Traditionally, homogeneous catalysts have been used in order to obtain the desired product in a reasonable amount of time and with a high selectivity. In this sense, homogeneous acids/bases and oxidants/reductants have been used in stoichiometric or catalytic amounts in multiple synthetic processes involving isomerization, condensation, oxidation or hydrogenation steps. However, when using these homogeneous catalysts, the costly separation of the 
catalyst and the neutralization-purification steps of the desired compound decrease the efficiency of the process due to waste formation. R. Sheldon defines waste as "everything but the desired product", with the exception of water. One way to quantify the amount of waste produced in a chemical synthesis is by the $\mathrm{E}$ (from environmental) factor as the mass of waste divided by the mass of product [1]. Once the waste produced is known, the $\mathrm{E}$ factor can be minimized using heterogeneous catalysis. Although the amount of chemicals produced in the fine chemical and pharmaceutical industries are not relatively high (compared with bulk chemicals), the E factor is about 1 or 2 orders of magnitude higher. To achieve sustainable fine chemicals and pharmaceuticals manufacture, the use of stoichiometric (mainly inorganic) reagents in organic synthesis needs to be substituted by (preferably heterogeneous) catalysts. However, due to the small volumes involved and to the use of the least expensive reagent, the implementation of waste reduction has not been as extensive as in the bulk chemicals industry. Nevertheless, in the last two decades more emphasis has been placed on the use of catalytic methods in organic synthesis. The particular use of MOFs and zeolites as heterogeneous catalysts for this type of organic transformations in order to improve their sustainability is illustrated in this chapter.

\section{MOFs and zeolites in acid catalysed reactions}

The main problem of typical homogeneous Lewis acid-catalysed reactions is the difficult handling of the catalysts due to the hazardous nature and high reactivity of such soluble compounds. Moreover, they have to be decomposed before their isolation from the reaction mixture in order to purify the product, which makes it impossible to reuse it and produces undesired wastes. Therefore, there is an urgent necessity to develop heterogeneous solid acid catalyst, to make the process more cost-effective with the possibility of reuse, operation in a continuous mode and to reduce the environmental impact. Porous solid materials like MOFs or Zeolites are ideal candidates for use as catalysts in this type of reaction, not only because of the presence of active Lewis and Brønsted acid sites in their structures, but also for the possibility of tuning them for the desired application. In the following, we provide examples of materials containing Lewis and Brønsted acids sites focusing on their catalytic application in fine chemistry. This chapter serves as a general introduction to the topic, readers are referred to reviews and references for a more detailed overview $[2,3-6]$. 


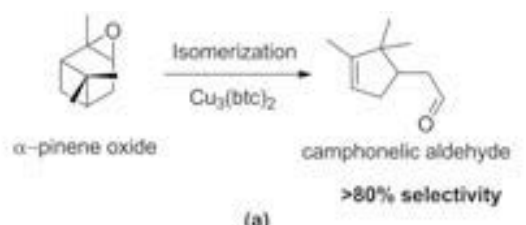

(a)

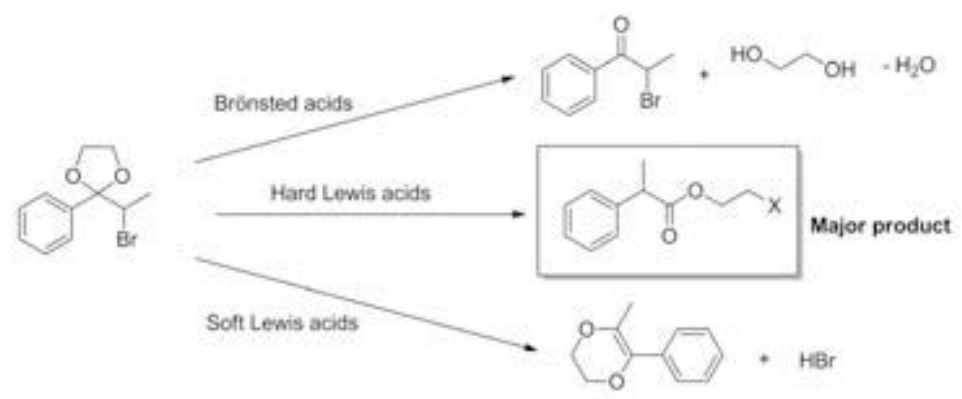

(b)

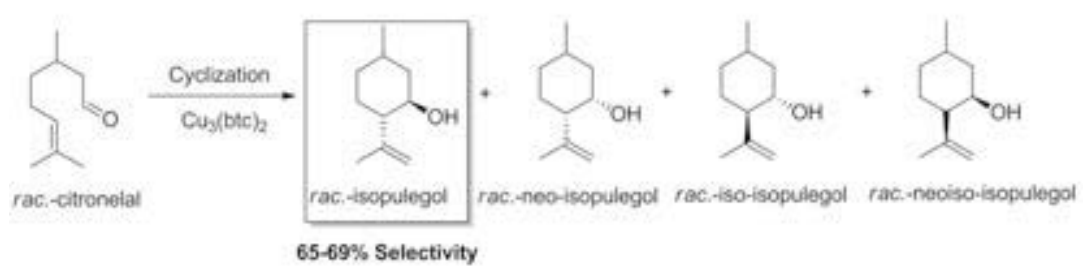

(c)

Figure 2. a) Isomerization of a-pinene oxide to campholenic aldehyde as the main product in the presence of Lewis acid sites of CUBTC, b) citronellal isomerization or cyclization towards the four different pulegols isomers (isopulegol as the main product) and c) reaction of 2-bromopropiophenone as a test to the nature and strength of the acid sites.

Typical reactions catalysed by Lewis and/or Brønsted acids sites are isomerizations. These are processes in which one molecule is transformed into another molecule, with exactly the same atoms, but a different arrangement (Figure 2, part a and c). There are multiple examples of isomerizations taking place in organic synthesis of fine chemicals such as fragrances or pharmaceuticals, especially in the terpene fraction of the biomass. For example, $\alpha$-pinene oxide or citronellal isomerization are well-studied reactions, that produce important fragrances. They are also popular test reactions to estimate the Brønsted or Lewis acid nature of the sites present in a solid catalyst. The strength of those Lewis acids can be estimated by using a cyclic acetal as a test substrate in the presence of the 
Lewis acids. The isomerization of $\alpha$-pinene oxide (Figure 2a) is a conventional way of producing campholenic aldehyde, which is an important intermediate used in the fragrance and pharmaceutical industry. Moreover, this reaction is a sensitive probe for the Lewis/Brønsted acid nature of the catalysts [7]. Briefly, Lewis acid sites catalyse the formation of campholenic aldehyde while the presence of Brønsted acidity lowers the selectivity towards this product. Dirk de Vos et al., [8] extended the study of the acid properties of $\mathrm{CuBTC}(\mathrm{BTC}=1,3,5$-benzenetricarboxylate) by determining which type of acid centres were present (Brønsted or Lewis, hard or soft). High selectivities in the isomerizations of $\alpha$-pinene oxide and citronellal clearly identify $\mathrm{Cu}_{3}(\mathrm{BTC})_{2}$ as a material with Lewis acid sites. By using the cyclic acetal of 2-bromopropiophenone as a test substrate, it was demonstrated that these sites are hard Lewis acid sites (Figure $2 b$ ). Results obtained for isomerization of $\alpha$-pinene oxide over some zeolites USY [9] and Ti-Beta [10] generates a $75 \%$ and $94 \%$ selectivity towards campholenic aldehyde at $100 \%$ and $95 \%$ conversion, respectively. A similar observation was made by Vermoortele et al., who used post-synthetic acid treatment (either $\mathrm{HClO}_{4}$ or $\mathrm{CF}_{3} \mathrm{COOH}$ ), to activate MIL-10o(Fe) [11] and test their catalytic performance in the $\alpha$-pinene oxide isomerization. Defect creation in acid modified materials, results in an increase of the Lewis and Brønsted acidity. During the reaction both, conversion and selectivity to campholenic aldehyde decrease was observed. This can be attributed to the increased amout of protonated carboxylate ligands inside cages of MOF, which might serves as weak Brønsted acid sites.

Cyclization of (+)-citronellal to (-)-isopulegol (Figure 2c) is an important intermediate reaction in (-)-menthol production. [12] Menthol is a naturally occurring compound in the essential oil of mint leaves, which is used for its medicinal, sensory and fragrant properties due to its action within the central nervous system. The generation of different diastereoisomeric products require not only active, but also diastereoselective heterogeneous catalyst. Citronellal cyclization to isopulegol is catalysed by both strong Lewis and weak Brønsted acid sites. Sn-Beta was employed for the first time in a reaction that involves carbon-carbon bond formation. The catalytic performance of the Sn Lewis acid sites in the zeolite matrix is much superior to conventional heterogeneous catalysts used for this reaction (Table 1). Moreover, this catalyst does not require the usual precautions against humidity needed for normal Lewis acids. The stability of the Sn-Beta zeolite makes the catalyst suitable for applications in a fixed bed continuous reactor [13] The superiority of the tin over other Lewis acids introduced into the zeolite framework is shown in Table 1 , where Ti-Beta gave lower conversion 
Table 1. Catalytic isomerization of citronellal using zeolites and MOFs.

\begin{tabular}{llccc}
\hline & Catalyst & Conversion & $\mathbf{S}_{\text {isopulegol }}$ & TOF $\left(\mathbf{h}^{-1}\right)$ \\
\hline 1 & Sn-Beta & $99 \%(1 \mathrm{~h})$ & $83 \%$ & 4575 \\
2 & Al-Beta & $50 \%(1 \mathrm{~h})$ & $53 \%$ & 73 \\
3 & Ti-Beta & $35 \%(1 \mathrm{~h})$ & $66 \%$ & 112 \\
4 & Cr-MIL-101 & $100 \%(18 \mathrm{~h})$ & $74 \%$ & $>1$ \\
5 & Pure Silica Beta & $0 \%(1 \mathrm{~h})$ & - & - \\
6 & 20\%HPW/MCM-41 & & \\
\hline
\end{tabular}

(entry 3). Additionally, the diastereoselectivity with respect to the isopulegol is much lower for the titanium containing material (compare entries 1 and 3). Brønsted-acidic Beta zeolite with a comparable hydrophobicity as Sn-Beta in the same reaction conditions also gave only cyclization without any side-products. However, the diastereoselectivity towards the desired product was again lower (entry 2 ) and the conversion was only $50 \%$ vs. full conversion for Sn-Beta. The origin of the activity in the Sn-Beta can be attributed to the tin since the all-silica Beta sample has no activity (entry 5).

Chuah and coworkers investigated the catalytic activity of Zr-zeolite Beta in this reaction [15] showing good activity for isopulegols formation, with more than $97 \%$ selectivity and high diastereoselectivity for isopulegol $(\sim 93 \%)$. The presence of Lewis and Brønsted acid sites, involved in the reaction mechanism was confirmed also by pyridine IR studies. MOF materials with Lewis acid sites, like MIL-101 [16] and $\mathrm{Cu}_{3}(\mathrm{BTC})_{2}[17]$ also have been tested. However they presented lower activity than Lewis acid zeolites (entry 4) or encapsulated heteropolyacids (entry 6) [14]. When the authors used the acid modified MIL-10o(Fe) to catalyse the isomerization of citronellal to isopulegol, they observed that the selectivity to isopulegol increased as more Brønsted acid sites were created, and attributed this observation to a dual Lewis-Brønsted acid site mechanism. However, lower diastereoselectivity for this material was achieved, compared to Zr- or Sn-beta zeolites.

\section{MOFs and zeolites in base catalyzed reactions}

As mentioned in the introduction, the pharmaceutical and chemical industries are continuously searching for processes with a lower environmental impact, not only for the use of greener solvents and reactants but also to limit the number of steps while safeguarding the purity and safety of high-quality but affordable therapeutic molecules. For most of the $\mathrm{C}-\mathrm{C}$ forming reactions 
that generate important fine chemicals and pharmaceuticals, stoichiometric amounts of base are normally required. However, the soluble base used as a catalyst (normally alkali, alkali earth metals, ammonium or organic basic salts) requires additional synthetic steps of neutralization and separation from the reaction mixture. Therefore, the use of heterogeneous catalysts simplifies the purification of the product and removal of the homogeneous catalyst counterpart. In fact, a deep knowledge has been achieved on the design of heterogeneous basic catalysts for carbon-carbon bond formation through condensation reactions [18-25]. One interesting example is the synthesis of jasminaldehyde perfume by the aldol condensation between benzaldehyde and heptanal. Vermoortele et al. [26] have described the use of the zirconium MOF UiO-66- $\mathrm{NH}_{2}$ as a bifunctional acid-base catalyst for the cross-aldol condensation between benzaldehyde and heptanal to produce jasminaldehyde. The amino groups of the ligand were proposed as the basic sites, while the acid sites were created in situ by controlled dehydroxylation of the material, creating coordination vacancies shared by three $\mathrm{Zr}^{4+}$ cations in the triangular faces of the inorganic cluster. The yields and conversions obtained with the UiO-66 dehydroxylated samples (Table 2, entries 1-4) were lower than those of bifunctional AlPOs [27] and various hydrotalcites [28] previously described (entries 5 and 6).

Condensation reactions, such as the aldol condensation just mentioned, are able to make $\mathrm{C}$ - $\mathrm{C}$ bonds in the synthesis of complex fine chemicals by the use of basic catalysts. The most frequently applied reaction for testing basic catalysts is a $\mathrm{C}-\mathrm{C}$ bond forming reaction known as the Knoevenagel reaction.

Table 2. Aldol condensation between benzaldehyde and heptanal performed on different catalysts.

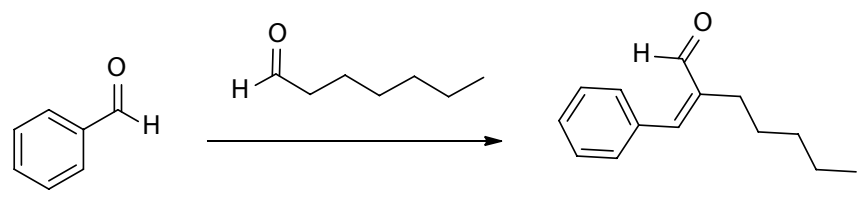

Jasminaldehyde

\begin{tabular}{llcll}
\hline & Catalyst & Conversion & S $_{\text {Jasminaldehyde }}$ & TOF $\left(\mathbf{h}^{-1}\right)$ \\
\hline 1 & UiO-66 Treated at 423 K in air & $30 \%(1 \mathrm{~h})$ & 85 & 0.5 \\
2 & UiO-66 Treated at 573 K in vacuum & $42 \%(1 \mathrm{~h})$ & 80 & 0.7 \\
3 & UiO-66- $\mathrm{NH}_{2}$ Treated at 423 K in air & $67 \%(1 \mathrm{~h})$ & 92 & 1.1 \\
4 & UiO-66- $\mathrm{NH}_{2}$ Treated at 473 K in air & $38 \%(1 \mathrm{~h})$ & 92 & 0.6 \\
5 & ALPO & $96 \%(3 \mathrm{~h})$ & 83 & 1.5 \\
6 & Hydrotalcite & $98 \%(8 \mathrm{~h})$ & 84 & 1 \\
\hline
\end{tabular}


The results of Corma and coworkers indicate that on AlPO surface, weak acid and basic sites coexist in adequate proportion in such way it should be possible that an acid-base bifunctional catalysis was operating [20]. Gascón et al. [29] demonstrated that MOFs with non-coordinated amino groups, such as IRMOF-3 can be use as solid basic catalysts for the Knoevenagel condensation of ethyl cyanoacetate with benzaldehyde. The results obtained with this material were good, attaining a yield of $99 \%$ after $2 \mathrm{~h}$, comparable with other MOF catalysts reported so far. However, the activity of inorganic solids with mobile $\mathrm{OH}^{-}$ions is much higher due to the favoured abstraction of the proton in alpha to the carbonyl group in ethyl cyanoacetate $[30,31]$.

\section{MOFs and zeolites in oxidation reactions}

Selective oxidation reactions are important processes in the fine chemical industry due to the possibility of functionalizing C-C bonds. Metal-catalysed oxidation processes can proceed through several kinds of mechanisms. In general, they can be simplified into two types: homolytic and heterolytic ones [32]. In homolytic oxidations, metal is oxidized outside the coordination sphere via a radical chain mechanism. This one-electron redox step set the role of catalyst as generator of organic radicals form substrate that react with molecular oxygen by an 'auto-oxidation' mechanism [33], forming peroxo radicals, able to initiate a new radical chain via the abstraction of hydrogen atom forming next substrate molecule (Figure 3). Heterolytic oxidations, involve substrate/oxidizing reagent activation for the nucleophilic attack, by coordination to the metal clusters. This is a two-electron redox change, where metal acts as a Lewis acid. In this section, we present examples of MOFs and Zeolites used in different oxidation reactions. Special attention is given to the selectivity and reusability of materials, and use of green oxidants like air, molecular oxygen and peroxides.

Thanks to the diversity of MOFs, many transition metals i.e. $\mathrm{Cr}, \mathrm{Mn}$, $\mathrm{Fe}, \mathrm{Co}, \mathrm{Cu}$ and $\mathrm{Ti}$ are usually used as oxidation catalyst once incorporated in the framework structure. This research is reflected by various reviews [34-36], where MOFs have been used to promote oxidation. Asefa and $\mathrm{Li}$ [37], have reported cobalt based MOF $\left[\mathrm{Co}(\mathrm{OBA})_{2}\left(\mathrm{H}_{2} \mathrm{O}\right)_{2}\right]\left(\mathrm{H}_{2} \mathrm{OBA}=\right.$ 4,4'-oxydibenzoic acid) as a highly active catalyst, for olefin epoxidation reactions. The material consists of a flexible $2 \mathrm{D}$ layered structure, which makes all of the active metal sites easily accessible for reactants. Water in the structure can be easily thermally removed, to give highly reactive open $\mathrm{Co}(\mathrm{II})$ centers (Lewis acid sites). The activity of dehydrated MOF was 
tested in solvent-free conditions and different aromatic olefins, with TBHP (tert-butyl hydroperoxide) as oxidant. In the case of styrene, the catalyst yielded $96 \%$ conversion and $96 \%$ of selectivity to styrene oxide at $75^{\circ} \mathrm{C}$. The reactivity of the epoxide ring makes these compounds important intermediates in the synthesis of fine chemicals and pharmaceuticals. To confirm the heterogeneous nature of this catalyst, the MOF catalyst was recovered and reused four times. A hot filtration experiment was also provided (in 4 cycles). Repeated reaction cycles gave similar conversions but slightly lower selectivity and some leaching of $\mathrm{Co}^{2+}$ was observed in the filtrate.

MIL-101(Cr) was reported for the first time by G. Férey [38] and is characterized by big pore size and surface area. It has a zeo-type cubic structure with very large cell volume (702,000 cubic angstroms). It is also claimed, to be one of the most stable MOFs. All these features, make it very promising material for liquid-phase oxidation reactions $[39,40,36]$, where big pore size can be helpful, to avoid diffusion control during the process. H. Garcia and coworkers reported the MOF MIL-101(Cr) as an active catalyst in benzylic oxidation of hydrocarbons [41]. In this experiment, indane was used as a model compound for oxidation, with molecular oxygen as the only oxidizing agent. The indanone product is part of the steroid biosynthesis and extensive studies on bioactivity of 1-indanone derivatives open up more and more new possibilities of their applications as pharmaceutically active ingredients. Selectivity, towards the alcohol/ketone mixture was higher for MIL-101(Cr) (87\% selectivity, 30\% conversion), compared to the same reaction on MIL-101 $(\mathrm{Fe})\left(71 \%\right.$ selectivity at $30 \%$ conversion) at $120^{\circ} \mathrm{C}$. The catalytic activity and crystallinity of this material, remains stable for up to four reuses. In the reaction mechanism, the metal nodes of the lattice interact with oxygen, forming metalloperoxides able to abstract a hydrogen

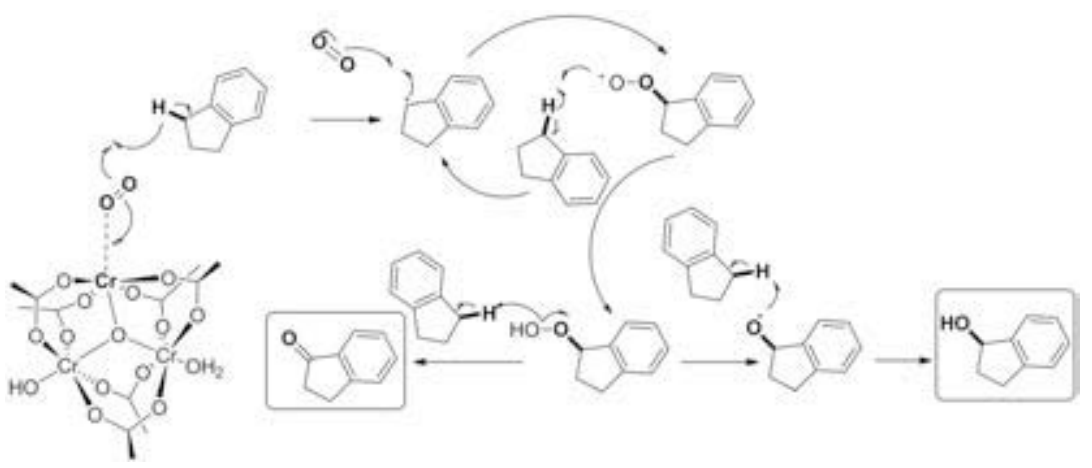

Figure 3. Mechanism proposed for the selective oxidation of alkenes to alcohols and ketones in the presence of oxygen and the $\mathrm{Fe}(\mathrm{Cr})-\mathrm{MIL}-101$ catalyst. 
atom form the benzylic position (Figure 3). High selectivity in this process can be explained, by reaction taking place inside the MOF pores, which favours adsorption of indane, and desorption of more polar products like indanol and indanone.

A copper-based MOF was reported by Pombeiro and coworkers, for selective oxidation of cyclopentane and cyclohexane [42]. The reaction was carried out at room temperature and atmospheric pressure, using hydrogen peroxide (in a slightly acidic medium) as oxidant. It has been shown, that MOF catalyst proceeds more efficiently in the presence of nitric acid (Table 3). This phenomenon can be explained, by the role of acid, in activations of catalyst by promoting unsaturated metal sites, which improves their oxidative properties. Increasing the amount of catalyst and hydrogen peroxide increased the percentage of conversion, leading (in the best case) to cyclohexanol $(25.1 \%)$ and cyclohexanone $(2.8 \%)$ as the only product of reaction.

Among zeolites, Titanium-Silicate-1 (TS-1) is the most widely used as a shape selective catalyst in oxidation reactions [43]. This material has hydrophobic properties, and its titanium active sites are tetrahedrally coordinated in MFI-lattice. Weak residual acidity properties make it a very selective catalyst in epoxidation reaction. However, TS-1 has medium pore size (5.5 $\AA$ ), which limits the scope of reaction to epoxidation of linear alkenes. For this reason many research groups have dedicated their work to incorporation of $\mathrm{Ti}$ into more open zeolite frameworks. $[44,45]$ The one-pot carbon-templating method was successfully used by Yang and Li et al., on synthesized mesoporous zeolite with transition-metal substitution, based on TS-1. To show the role of mesopores in the catalytic performance, TS-1 (meso-TS-1) and conventional microporous TS-1 were compared in a two model reaction phenol hydroxylation and methyl ethyl ketone ammoxiation [46] using $\mathrm{H}_{2} \mathrm{O}_{2}$ as an oxidant in both cases. No difference in selectivity was observed, which is strongly related to similar microenvironment of titanium species in meso-TS-1 and TS-1 zeolite. However, a difference in catalytic performance

Table 3. Acid-to-Catalyst molar ratio effect in the oxidation of cyclohexane over the Cu MOF.

\begin{tabular}{lcc}
\hline $\mathbf{n}\left(\mathrm{HNO}_{3}\right) / \mathbf{n}$ (catalyst) & Cyclohexanol Yield (\%) & Cyclohexanone Yield (\%) \\
\hline 5 & 6.1 & 0.3 \\
10 & 25.1 & 2.8 \\
30 & 13.7 & 15.3 \\
\hline
\end{tabular}


is related to textural properties, by the authors. Detail analysis by ${ }^{129} \mathrm{Xe} \mathrm{NMR}$ spectroscopy combined with TEM and $\mathrm{N}_{2}$ sorption results proved the existence of mesopores in meso-TS-1 and their good connectivity with micropores, which can increase the diffusion rate significantly, and in consequence lead to better catalytic activity of meso-TS-1 compared to TS-1.

Incorporation of $\mathrm{Bi}$ into the framework of mesoporous material has been reported by Qi et al. Mesoporous Bi-MCM-41 was synthesized under strongly acidic conditions. Catalytic activity was tested in cyclohexane oxidation [47] To make the system environmentally friendly, the reaction was carried out in a solvent-free system, using oxygen as an oxidant $(1 \mathrm{MPa})$ at $15^{\circ}{ }^{\circ} \mathrm{C}$. To prove the true active role of bismuth ions, blank reaction was carried out as catalyst on Si-MCM-41, with no observed catalytic activity. Samples with different bismuth contents were tested, showing that $1.4 \mathrm{wt} . \%$ metal content is the optimum for the best catalytic performance. Increasing bismuth content does not improve oxidation rate due to change in the kind of bismuth species or distribution of this metal in the catalyst. No leaching of metal was detected, indicating good stability of this catalyst, in up to three runs, compared to Au/MCM-41 [48] and Au/ZSM-5 [49]. This can be explained by a good distribution of metal in the Bi-MCM-41 internal surface, showed by XPS analysis.

\section{MOFs and zeolites in reduction reactions}

An important reaction in the perfume, flavouring, agrochemical and pharmaceutical industries is the selective reduction of the carbonyl group of an $\alpha, \beta$-unsaturated ketone. The resulting allylic alcohols find a wide range of applications, for example as intermediates in the synthesis of fine chemicals $\left[5^{\circ}-53\right]$ and for the production of the chemically very versatile oxiranes, as described in the last section [54-57]. To reduce the carbonyl group of an $\alpha, \beta$-unsaturated ketone to a hydroxy group, without affecting the conjugated $\mathrm{C}-\mathrm{C}$ double bond, different methods have been developed [58-61]. Besides catalytic hydrogenolysis with hydrogen as the reducing agent [62-68] an alternative method is Meerwein-Ponndorf-Verley (MPV) reduction, which traditionally employs an alcohol as a hydride source and aluminum alkoxides as a catalyst $[69,70]$. The choice of Lewis acid is the key to improving the reactions in terms of chemical selectivity, reaction temperature, reaction rate, the amount of catalyst needed, the reusability of the catalyst and the process of product isolation. In respect to the latter two aspects, heterogeneous catalysis is the most appealing. Zr or Hf 
functionalized mesoporous silica [71-73], Sn containing zeolites $[74,75]$ and metal-organic frameworks $[76,77]$ have been reported as a substitute for the MPV reduction. Metal-organic frameworks (MOFs) have recently attracted interest as heterogeneous catalysts due to their structural diversity, high surface area and different types of active sites [3,11,29,78-84]. MOFs are composed of metal (oxide) nodes interlinked by organic ligands that form three-dimensional periodic structures with well-defined micropores and pore channels [85-88]. However, there are a few reports on the selective reduction of unsaturated carbonyl compounds with $\mathrm{H} 2$ and MOF as support for noble metal nanoparticles [66,67], due to the low selectivity towards the reduction of the carbonyl group. Recently, the Zr MOFs UiO-66 and MOF- 808 were shown to catalyse the hydrogen transfer from secondary alcohols to $\alpha, \beta$-unsaturated carbonyl compounds in a Meerwein-PonndorfVerley reduction, reducing the carbonyl group without affecting the $\mathrm{C}=\mathrm{C}$ double bond $[89,90]$. However, the performance of $\mathrm{Zr}-$ or Sn-Beta is much better in terms of activity.

Catalytic reduction has been applied to obtain $\gamma$-valerolactone, a high value-added levulinic acid derivative in fine chemistry. Gamma valerolactone (GVL) could be considered as a sustainable liquid for global storage/transportation and a renewable hydrocarbon resource for energy and carbon-based consumer products as described elsewhere [91]. The production of gamma valerolactone (also known as 5-methylbutyrolactone or 5 -valerolactone) as a renewable feedstock is interesting due to a much lower vapor pressure, (compared to methanol, ethanol, and methyl and ethyl tert-butyl ethers) which reduces volatile emissions and facilitates safe storage. On the other hand GVL has a high chemical stability, which avoids hydrolization to the acid form and the formation of peroxides under pH-neutral conditions. Moreover, because GVL does not form an azeotrope with water, less energy is needed to recover it through distillation. These properties enhance its general use as fuel additive to produce cleanerburning fuels [91], or as intermediate in the production of chemicals such as adipic acid [92], valeric acid [93,94], 5-nonanone [95], in the composition of biocides [96] and as a solvent [97]. There are multiple pathways to produce GVL, as described elsewhere [98]. Among them, the majority of the processes make use of levulinic acid (LA) as starting material [99]. The interest of using LA as a precursor of GVL is because of the huge availability of such a renewable compound, which proceeds from the deconstruction of biomass. An alternative to the use of hydrogen gas or formic acid in the synthesis of GVL takes place in the chemoselective reduction of the keto group of LA by hydrogen transfer from a secondary alcohol as a hydrogen source through a 
Table 4. MPV reduction of levulinic acid by various catalysts at moderate reaction temperatures [100].

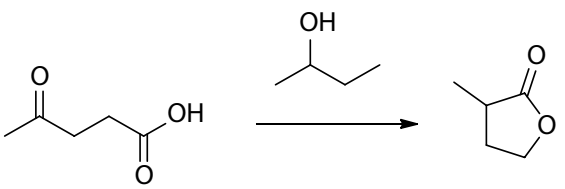

\begin{tabular}{|c|c|c|c|c|c|}
\hline & Catalyst & Temp. $\left({ }^{\circ} \mathrm{C}\right)$ & Conversion (\%) & $\mathbf{S}_{\mathrm{GVL}}(\%)$ & TOF $\left(h^{-1}\right)$ \\
\hline 1 & MOF-808 & 130 & 100 & 85 & 7.7 \\
\hline 2 & UiO-66(Zr) & 130 & 43.3 & 18 & 0.8 \\
\hline 3 & $\mathrm{ZrO}_{2}$ & 130 & 36.5 & 60 & 0.2 \\
\hline 4 & Zr-Beta & 118 & 88 & 94 & 3.7 \\
\hline
\end{tabular}

Meerwein-Ponndorf-Verley (MPV) reaction. The use of the zirconium MOFs with MPV catalytic activity in the MPV reduction of LA to GVL by using secondary alcohols as hydrogen source has recently been described.

On the other hand, bimetallic $\mathrm{Zr}(\mathrm{Ti})$-NDC based metal-organic frameworks (MOFs) have been prepared by incorporation of titanium(IV) into zirconium(IV)-NDC-MOFs (UiO family). The resulting materials maintain thermal (up to $50^{\circ}{ }^{\circ} \mathrm{C}$ ), chemical and structural stability with respect to parent Zr-MOFs as can be deduced from XRD, $\mathrm{N}_{2}$ adsorption, FTIR and thermal analysis. The materials have been studied in Lewis acid catalysed reactions, such as domino Meerwein-Ponndorf-Verley (MPV) reduction-etherification of $p$-methoxybenzaldehyde with butanol. In general, for activity in the MPV reaction, coordinative unsaturated (Lewis acid) Zr sites, which can react with an alcohol to form an activated alkoxide specie, are required. Zeolite $\mathrm{Zr}$ - and Sn-Beta is an excellent catalyst for the MPV due to the high activity with respect to the MOFs (entry 4 of Table 5 and entries 2 and 3 of Table 5 ). This indicates stronger Lewis sites than in the case of the $\mathrm{Zr}$ oxo-clusters of the UiO MOF, although the MOF-808 shows promising Lewis acid sites (entry 1 of Table 4 ).

\section{Conclusions and outlook}

This chapter has shown multiple applications of MOFs and zeolites in the transformation of different functional groups present in organic molecules. The potential catalytic sites present in the structure of these porous solids 
Table 5. MPV reduction-etherification of benzaldehyde with butanol preformed over different catalysts [101].

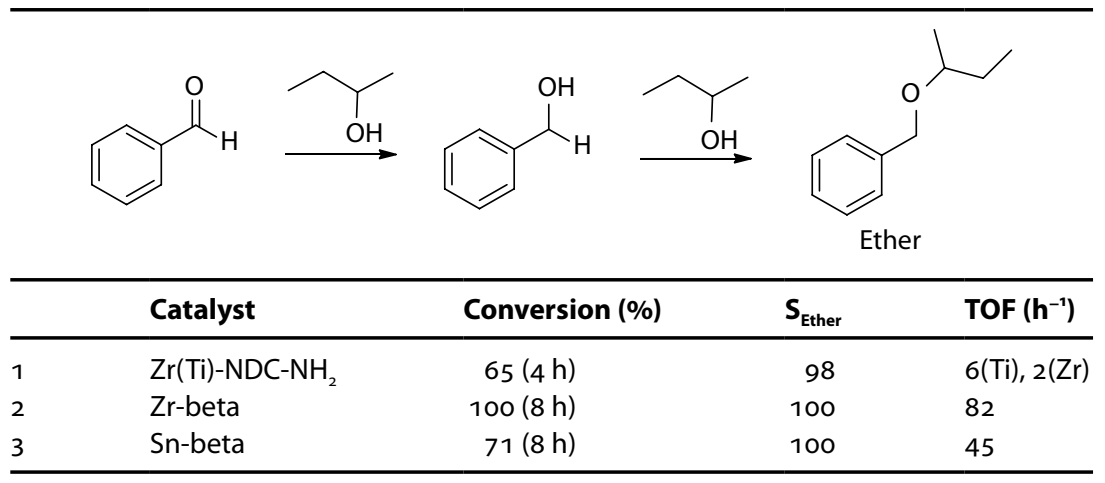

are able to selectively transform the desired functionality into a new one of industrial interest. Examples of active and selective crystalline and porous solids in isomerization, condensation, oxidation or hydrogenation using clean oxygen and hydrogen sources has been highlighted. The advantages of the solid catalyst, preferably in low amounts, are its non-toxicity, simple handling and separation from the reaction mixture. This fact allows up-scaling of the fine chemical and pharmaceutical synthesis from laboratory batch to a continuous industrial process. Relevant compounds that are obtained by classical organic chemistry reactions with the use of MOFs and zeolites as heterogeneous catalysts are fragances and pharmaceutically active compounds. Due to the relatively low attention the heterogeneous catalysis community has paid to synthetic organic transformations, the use of porous solids in organic and medicinal chemistry is currently a promising field of research with industrial applications. Therefore, in the coming years, the collaboration between solid state and organic chemists will produce synergic effects in the development of cleaner and more efficient organic transformations. This will eventually reduce the cost of the synthesis of complex molecules, as nature has done since life began on the planet, thanks to highly optimized enzymes than contain similar functions and structures to those present in the solids we prepare in the laboratory. Although we still far from imitate metabolic routes in animal and plant cells, silicates (zeolites and mesoporous silicas) and metal-organic frameworks are more robust and economic than natural enzymes, which enable us to work under a broad range of conditions. In the near future, we will be able to accurately mimic the active sites of most of the enzymes and then it 
will be possible to optimize the organic transformations for the synthesis of fine chemicals and pharmaceuticals and minimize health and environmental impact with the use of finely tuned supramolecular catalysts designed and synthetized by chemists.

\section{References}

[1] Sheldon, R.A. Green Chem. 2017, 9, 903.

[2] Corma, A., García, H., Llabrés i Xamena, F.X. Chem. Rev. 2010, 110, 4606.

[3] Jiang, J., Yaghi, O.M. Chem. Rev. 2015, 6966.

[4] Corma, A., García, H. Chem. Rev. 2003, 103, 4307.

[5] Hu, Z., Zhao, D. Cryst. Eng. Comm. 2017, 19, 4066.

[6] Rabo, J.A., Gajda, G.J. Catal. Rev. 1989, 31, 385.

[7] Rachwalik, R., Olejniczak, Z., Jiao, J., Huang, J., Hunger, M., Sulikowski, B. J. Catal. 2007, 252,161 .

[8] Alaerts, L., Séguin, E., Poelman, H., Thibault-Starzyk, F., Jacobs, P.A., De Vos, D.E. Chem. Eur. J. 2006, 12, 7353 .

[9] Hölderich, W.F., Röseler, J., Heitmann, G., Liebens, A.T. Catal. Today 1997, 37, 353.

[10] Kunkeler, P.J., van der Waal, J.C., Bremmer, J., Zuurdeeg, B.J., Downing, R.S., van Bekkum, H. Catal. Lett. 1998, 53, 135 .

[11] Vermoortele, F., Ameloot, R., Alaerts, L., Matthessen, R., Carlier, B., Fernandez, E.V.R., Gascon, J., Kapteijn, F., De Vos, D.E. J. Mater. Chem. 2012, 22, 10313.

[12] Gotz, N., Friedrich, M., Ebel, K. ES Patent 2352346, 2011.

[13] Corma, A., Renz, M. Chem. Commun. 2004, 5, 550.

[14] Braga, P.R.S., Costa, A.A., De Freitas, E.F., Rocha, R.O., De MacEdo, JL., Araujo, A.S., Dias, J.A., Dias, S.C.L.J. Mol. Catal. A Chem. 2012, 358, 99.

[15] Yongzhong, Z., Yuntong, N., Jaenicke, S., Chuah, G.K.J. Catal. 2005, 229, 404.

[16] Cirujano, F.G., Llabrés i Xamena, F.X., Corma, A. Dalton Trans. 2012, 41, 4249.

[17] Vandichel, M., Vermoortele, F., Cottenie, S., De Vos, D.E., Waroquier, M., Van Speybroeck, V. J. Catal. 2013, 305, 118 .

[18] Akutu, K., Kabashima, H., Seki, T., Hattori, H. Appl. Catal., A 2003, 247, 65.

[19] Corma, A., Martín-Aranda, R.M., Sánchez, F.J. Catal. 1990, 126, 192.

[20] Climent, M.J., Corma, A., Iborra, S., Velty, A.J. Mol. Catal. A Chem. 2002, 182, 327.

[21] Corma, A., Fornes, V., Martin-Aranda, R.M., Garcia, H., Primo, J. Appl. Catal. 1990, 59, 237.

[22] Climent, M.J., Corma, A., Fornés, V., Guil-López, R., Iborra, S. Adv. Synth. Catal. 2002, 344, 1090.

[23] Gianotti, E., Diaz, U., Velty, A., Corma, A. Catal. Sci. Technol. 2013, 3, 2677.

[24] Shylesh, S., Wagener, A., Seifert, A., Ernst, S., Thiel, W.R. Angew. Chem. Int. Ed. 2010, 49, 184.

[25] Corma, A., Garcia, H. Adv. Synth. Catal. 2006, 348, 1391.

[26] Vermoortele, F., Ameloot, R., Vimont, A., Serre, C., De Vos, D. Chem. Commun. 2011, 47, 1521.

[27] Climent, M.J., Corma, A., Garcia, H., Guil-Lopez, R., Iborra, S., Fornés, V.J. Catal. 2001, 197, 385.

[28] Sharma, S.K., Parikh, P.A., Jasra, R.V.J. Mol. Catal. A Chem. 2008, 286, 55.

[29] Gascon, J., Aktay, U., Hernandez-Alonso, M., Vanklink, G., Kapteijn, F. J. Catal. 2009, 261, 75.

[30] Climent, M.J., Corma, A., Iborra, S., Epping, K., Velty, A.J. Catal. 2004, 225, 316.

[31] Rodriguez, I., Iborra, S., Rey, F., Corma, A. Appl. Catal., A 2000, 194, 241.

[32] Sheldon, R.A., Kochi, J.K. Met. Oxidations Org. Compd. 1981, 1.

[33] Hsu, Y.F., Cheng, C.P.J. Mol. Catal. A Chem. 1998, 136, 1. 
[34] Dhakshinamoorthy, A., Alvaro, M., Garcia, H. Catal. Sci. Technol. 2011, 1, 856.

[35] Dhakshinamoorthy, A., Asiri, A.M., Garcia, H. Chem. Eur. J. 2016, 22, 8012.

[36] Kholdeeva, O.A. Catal. Today 2016, 278, 22.

[37] Zhang, J., Biradar, A.V, Pramanik, S., Emge, T.J., Asefa, T., Li, J. Chem. Commun. 2012, 48, 6541.

[38] Férey, G., Mellot-Draznieks, C., Serre, C., Millange, F., Dutour, J., Surblé, S., Margiolaki, I. Science 2005, 309, 2040.

[39] Skobelev, I.Y., Sorokin, A.B., Kovalenko, K.A., Fedin, V.P., Kholdeeva, O.A. J. Catal. 2013, 298, 61.

[40] Kholdeeva, O.A., Skobelev, I.Y., Ivanchikova, I.D., Kovalenko, K.A., Fedin, V.P., Sorokin, A.B. Catal. Today 2014, 238, 54 .

[41] Santiago-Portillo, A., Navalón, S., Cirujano, F.G., Llabrés i Xamena, F.X., Alvaro, M., Garcia, H. ACS Catal. 2015, 5, 3216.

[42] Nicola, C. Di, Karabach, Y.Y., Kirillov, A.M., Monari, M., Pandolfo, L., Pettinari, C., Pombeiro, A.J.L. Inorg. Chem. 2007, 46, 221.

[43] Clerici, M.J. Catal. 1993, 71.

[44] Wu, P., Tatsumi, T. J. Phys. Chem. B 2002, 106, 748.

[45] Wu, P., Tatsumi, T.J. Catal. 2003, 214, 317.

[46] Xin, H., Zhao, J., Xu, S., Li, J., Zhang, W., Guo, X., Hensen, E.J.M., Yang, Q., Li, C.J. Phys. Chem. C 2010, 114, 6553 .

[47] Qian, G., Ji, D., Lu, G.M., Zhao, R., Qi, Y.X., Suo, J.S.J. Catal. 2005, 232, 378.

[48] Lu, G.M., Zhao, R., Qian, G., Qi, Y.X., Wang, X.L., Suo, J.S. Catal. Lett. 2004, 97, 115.

[49] Zhao, R., Ji, D., Lv, G., Qian, G., Yan, L., Wang, X., Suo, J. Chem. Commun. 2004, 904.

[50] Saudan, L.A. Acc. Chem. Res. 2007, 40, 1309.

[51] Chapuis, C., Jacoby, D. Appl. Catal., A 2001, 221, 93.

[52] Cherkaoui, H., Soufiaoui, M., Grée, R. Tetrahedron 2001, 57, 2379.

[53] Kurosu, M., Marcin, L.R., Grinsteiner, T.J., Kishi, Y.J. Am. Chem. Soc. 1998, 120, 6627.

[54] Bisogno, F.R., Orden, A.A., Pranzoni, C.A., Cifuente, D.A., Giordano, O.S., Kurina Sanz, M. Steroids 2007, 72, 643 .

[55] Chen, C., Yuan, H., Wang, H., Yao, Y., Ma, W., Chen, J., Hou, Z. ACS Catal. 2016, 6, 3354.

[56] Hussain, M.M., Walsh, P.J. Acc. Chem. Res. 2008, 41, 889.

[57] Hanson, R.M., Sharpless, K.B.J. Org. Chem. 1986, 51, 1922.

[58] Walker, E.R.H. Chem. Soc. Rev. 1976, 5, 23.

[59] Ide, M.S., Hao, B., Neurock, M., Davis, R.J. ACS Catal. 2012, 2, 671.

[6o] Lumbroso, A., Cooke, M.L., Breit, B. Angew. Chem. Int. Ed. 2013, 52, 1890.

[61] Sakaguchi, S., Yamaga, T., Ishii, Y.J. Org. Chem. 2001, 66, 4710.

[62] Milone, C., Ingoglia, R., Tropeano, M.L., Neri, G., Galvagno, S. Chem. Commun. 2003, 7, 868.

[63] Mertens, P.G.N., Vandezande, P., Ye, X., Poelman, H., Vankelecom, I.F.J., De Vos, D.E. Appl. Catal., A 2009, 355, 176.

[64] Santori, G.F., Moglioni, A.G., Vetere, V., Iglesias, G.Y.M., Casella, M.L., Ferretti, O.A. Appl. Catal., A 2004, 269, 215.

[65] De bruyn, M., Coman, S., Bota, R., Parvulescu, V.I., De Vos, D.E., Jacobs, P.A. Angew. Chem. Int. Ed. 2003, 42, 5333 .

[66] Guo, Z., Xiao, C., Maligal-Ganesh, R.V., Zhou, L., Goh, T.W., Li, X., Tesfagaber, D., Thiel, A., Huang, W. ACS Catal. 2014, 4, 1340.

[67] Liu, H., Li, Z., Li, Y. Ind. Eng. Chem. Res. 2015, 54, 1487.

[68] Zhao, M., Yuan, K., Wang, Y., Li, G., Guo, J., Gu, L., Hu, W., Zhao, H., Tang, Z. Nature 2016, 539,76 .

[69] Cha, J.S. Org. Process Res. Dev. 2006, 10, 1032.

[70] Ruiz, J., Jimenez-Sanchidrian, C. Curr. Org. Chem. 2007, 11, 1113.

[71] De bruyn, M., De Vos, D.E., Jacobs, P.A. Adv. Synth. Catal. 2002, 344, 1120. 
[72] Zhu, Y., Jaenicke, S., Chuah, G.J. Catal. 2003, 218, 396.

[73] Iglesias, J., Melero, J., Morales, G., Moreno, J., Segura, Y., Paniagua, M., Cambra, A., Hernández, B. Catalysts 2015, 5, 1911.

[74] Corma, A.J. Catal. 2003, 215, 294.

[75] Corma, A., Domine, M.E., Nemeth, L., Valencia, S.J. Am. Chem. Soc. 2002, 124, 3194.

[76] Rasero-Almansa, A.M., Iglesias, M., Sánchez, F. RSC Adv. 2016, 6, 106790.

[77] Valekar, A.H., Cho, K.H., Chitale, S.K., Hong, D.Y., Cha, G.Y., Lee, U.H., Hwang, D.W., Serre, C., Chang, J.S., Hwang, Y.K. Green Chem. 2016, 18, 4542.

[78] Choi, K.M., Na, K., Somorjai, G.A., Yaghi, O.M.J. Am. Chem. Soc. 2015, 137, 7810.

[79] Goesten, M.G., Juan-Alcañiz, J., Ramos-Fernandez, E.V., Sai Sankar Gupta, K.B., Stavitski, E., van Bekkum, H., Gascon, J., Kapteijn, F. J. Catal. 2011, 281, 177.

[8o] Rösler, C., Fischer, R.A. Cryst. Eng. Comm. 2015, 17, 199.

[81] Valvekens, P., Vermoortele, F., De Vos, D. Catal. Sci. Technol. 2013, 3, 1435.

[82] Chen, Y.Z., Jiang, H.L. Chem. Mater. 2016, 28, 6698.

[83] Li, Y., Zhou, Y.X., Ma, X., Jiang, H.L. Chem. Commun. 2016, 52, 4199.

[84] Wee, L.H., Lescouet, T., Fritsch, J., Bonino, F., Rose, M., Sui, Z., Garrier, E., Packet, D., Bordiga, S., Kaskel, S., et al. Catal. Lett. 2013, 143, 356.

[85] Canivet, J., Fateeva, A., Guo, Y., Coasne, B., Farrusseng, D. Chem. Soc. Rev. 2014, 5594.

[86] Jiang, J., Zhao, Y., Yaghi, O.M. J. Am. Chem. Soc. 2016, 138, 3255.

[87] Goesten, M.G., Kapteijn, F., Gascon, J. Cryst. Eng. Comm. 2013, 15, 9249.

[88] Hirschle, P., Preiß, T., Auras, F., Pick, A., Völkner, J., Valdepérez, D., Witte, G., Parak, W.J., Rädler, J.O., Wuttke, S. Cryst. Eng. Comm. 2016, 18, 4359.

[89] Plessers, E., De Vos, D.E., Roeffaers, M.B.J.J. Catal. 2016, 340, 136.

[9o] Plessers, E., Fu, G., Tan, C., De Vos, D., Roeffaers, M. Catalysts 2016, 6, 104.

[91] Horváth, I.T., Mehdi, H., Fábos, V., Boda, L., Mika, L.T. Green Chem. 2008, 10, 28.

[92] Castelijns, A.M.C.F., Janssen, M.C.C., Vaessen, H.W.L.M. WO2012175439 Al, 2012.

[93] Palkovits, R. Angew. Chem. Int. Ed. 2010, 49, 4336.

[94] Lange, J.P., Price, R., Ayoub, P.M., Louis, J., Petrus, L., Clarke, L., Gosselink, H. Angew. Chem. Int. Ed. 2010, 49, 4479 .

[95] Serrano-Ruiz, J.C., Wang, D., Dumesic, J.A. Green Chem. 2010, $12,574$.

[96] Merlet, S., Scherer, M. EP Patent 236459oAl, 2011.

[97] Fegyverneki, D., Orha, L., Láng, G., Horváth, I.T. Tetrahedron 2010, 66, 1078.

[98] Serrano-Ruiz, J.C., West, R.M., Dumesic, J.A. Annu. Rev. Chem. Biomol. Eng. 2010, 1, 79.

[99] Wright, W.R.H., Palkovits, R. ChemSusChem 2012, 5, 1657.

[100] Wang, J., Jaenicke, S., Chuah, G.K. RSC Adv. 2014, 4, 13481.

[101] Corma, A., Renz, M.A. Angew. Chem. Int. Ed. 2007, 46, 298. 
